\title{
Photographic Disclosure in Facebook and Relational Closeness with Others
}

\author{
David Houghton \\ Birmingham Business \\ School, UK \\ HoughtDJ@bham.ac.uk
}

\author{
Adam Joinson \\ A.Joinson@bath.ac.uk \\ Nigel Caldwell \\ Heriot-Watt University, \\ UK \\ n.d.caldwell@hw.ac.uk
}

\author{
Ben Marder \\ Edinburgh Business \\ School, UK \\ Ben.Marder@ed.ac.uk
}

\author{
Emily Collins \\ University of Bath, UK \\ e.i.m.collins@bath.ac.uk
}

\begin{abstract}
Prior research has identified the usefulness of social media in the maintenance of relationships. Such research is predominantly based on overall platform use, the use and affordances of multiple different communication features, or the text-based content of disclosed messages. Little research exists into the disclosure effects of different photographic content, the frequency at which it is shared and how this associates with differences in relational closeness. This research gap becomes increasingly poignant with the mass adoption of social media, the existence of multiple relationship types within these platforms, and the increase in sites based on photographic disclosure alone. This research examines the implications of the perceived frequency of disclosure in Facebook on relational closeness with different relationship types. Survey findings $(N=445)$ show that perceived frequency of posting photographs is significantly associated with changes in relational closeness (companionship, intimacy, support), differing by the relationship held and the photographic depiction.
\end{abstract}

\section{Introduction}

Social Network Site (SNS) use is ubiquitous. Facebook has over 1.79 billion active monthly users [1], half of whom have over 200 'friends' [2] internalizing many different relationship types, e.g. friends, family and partners [3,4]. Facebook allows communication with this eclectic network of 'friends' through multiple features including status updates, wall posts, sharing photos and commenting on the posts of others. Through academic enquiry, it is established that use of- and disclosure through- such Facebook features is associated with positive relational effects between both 'friends' in general $[3,5,6]$ and specific types of friends $[7,8]$.
Although such studies provide important insight, they neglect to examine the disclosure of specific forms of non-text based content (e.g. photographs). For example, previous work has focused on textbased disclosure (e.g. language style [7]), the amount of interaction through individual Facebook features (e.g. number of photos, number of friends; [8,9]), or needs and disclosure more generally [10]. As such, this gap in knowledge is pressing given the widespread posting of photographs on SNS such as Facebook, and increasingly important with the rise of more niche sites with the raison d'etre of photo sharing, such as Instagram [11].

To address this gap, this study will examine the association between disclosure of different photographic depictions and relational closeness for multiple others. The present research investigates disclosure effects from the under-examined perspective of the recipient in isolation to the sender [12].

\section{Background}

The link between disclosure and closeness in offline environments is largely understood. Disclosure "begets" disclosure [13], and disclosure becomes increasingly intimate between interaction partners as a relationship progresses [14,15]. In addition, the content of disclosure can change throughout the development of a relationship, and content differs because of the type of relationship an individual has with others, e.g. friend, mother or father $[14,16]$. Disclosure can act as an antecedent, process or outcome of intimacy, such that the degree to which an individual likes or is liked is affected by disclosure to others [17].

More recently, studies of self-disclosure have identified differences in- and because of- ComputerMediated Communication (CMC) compared with Face-to-Face (FtF) interaction. Largely, the findings suggest that the lack of cues in CMC compared with 
FtF can help individuals to become better acquainted in $\mathrm{CMC}$, although this acquaintance may take longer to form and rely on more question asking $[18,19]$. However, as online communication platforms have begun to incorporate richer, more detailed cues to identity and behaviour (e.g. near-synchronous photo, video and text sharing), the findings of CMC have needed to be re-tested, as it cannot be assumed that the same underlying processes are still enacted [20].

Similar results are found to exist. Individuals can develop and maintain relationships on SNS [5,6], with these richer features (e.g. text, photo, video) acting as signals to users regarding desired levels of interaction or closeness [21]. However, this prior research investigates disclosure related to the affordances of features themselves (e.g. private vs. public; $[9,22])$, the amount these features are used $[8,23]$, or text-based interactions $[7,8,24]$. Thus, little attention has been paid to the details within interactions that are not count, or text-based, i.e. the content and frequency at which photographs are disclosed.

\subsection{Facebook, disclosure and relationships}

Facebook use has been linked with successful relational maintenance. In an investigation of social capital, [5] found their college sample to use Facebook to connect with those they knew offline, suggesting a continuance of the relationship online. Similarly, [6] found Facebook to be commonly used to 'keep in touch' with others. Facebook use may also serve a relationship development function, moving users closer together. In their investigation of self-disclosure and intimacy, [10] found that the amount of self-disclosure on Facebook was one of the factors associated with increased intimacy between users. Similarly, [3] found self-disclosure predisposition to relate to increased Facebook communication, and subsequently increased relational closeness. [25] used predictive modelling of social media data to establish intensity (increased interaction with another) as a marker of relational closeness (a strong tie).

The recency of the communication and number of Facebook features used between users was also related to increased relational closeness [8], with the authors stating that, "communication absence from each other's life corresponds to alienation and relational de-escalation". This shows not only that frequent communication is necessary, but a lack of communication through Facebook can also be detrimental to relational closeness. Indeed, [26] found a lack of communication recency to be more detrimental to closeness in friendship than kinship.
Thus, communication and disclosure frequency may not always be associated with positive relational effects. When investigating the norms and expectations of Facebook use amongst friends, [27] found it was important for users to respect their "friends' time by not posting to excess information on Facebook". [23] found that increased Facebook use does not necessarily mean increased intimacy, noting that Facebook and SNS in general could be both "helpful and harmful" for relationships, determined by the way in which they are used by the individuals. Each of these studies is akin to the notion of Digital Crowding, such that recipients of disclosure by others in online environments can be made to feel crowded when information is shared to excess or to an inappropriate depth for their relationship [28]. Whilst these studies have established that over-crowding through frequent information posting can have detrimental relational outcomes, the role of specific content is yet to be established.

What literature exists focuses on Facebook features generally or text-based communication. With regards to the former, [29] have found disclosing through a variety of features can successfully communicate affection and social support. Expressions would occur through 29 mechanisms on Facebook, but included public features, such as writing on their wall, and sending them a private message. [9] found that the way different features are afforded for disclosure can alter the receiver's perception of the message (i.e. private messenger is more intimate than public communication; see also [22]). With regard to the general sharing of photographs, [30] found that increased sharing is associated with greater network size, and greater social support, reaffirming the use of photographs for relational benefits. However, their investigation did not identify differences in the content of those posted photographs. While [31] investigated user reactions to branded content images, their lens was that of social anxiety and its later restrictive effect on user posting. With regards to text-based communication, [8] conducted a linguistic analysis on the text within Facebook status updates and comments on others' posts, and find no association between the use of language and relationship development. However, they did not investigate the frequency that language was used, suggested to be a key determinant of relational development by the literature already discussed.

Overall relational effects on Facebook have received much attention but little is still known about the effects of specific content sharing. In particular, no research has addressed the association between the 
sharing of different types of photographic depictions on relationship closeness, and although [32] addressed the differences in sharing practices of different types of photographs, they did not exam the association with relational closeness. Thus, we ask:

RQ1: Does different photographic (a) content (depictions), and (b) the perceived frequency at which these photographs are posted associate with relational closeness?

Facebook users have multiple relationship types, or audiences, within their 'friend' network [3,33], who may have different expectations of their sharing behaviour [34]. The effects of communication have been found to have both positive and negative outcomes across different relational types, based on frequency and recency $[8,26]$ and the general content that is shared [4,29,33]. These studies highlight the importance of investigating different relational types in examinations of disclosure. However, they neglect to address disclosure of specific non-text based communications (i.e. photographic depictions) on relational closeness. Thus, the following questions is proposed:

RQ2: How do the relationship type with the sender and the photograph depictions they post associate with relational closeness?

This study takes on the perspective of the recipient of photo sharing as it is (a) the under researched perspective [12]; and (b) important to identify how users may react to the photographs that are shared and to gather their perspective of the relationship given the little control they have over the number of different photographs they will receive from their Facebook 'friends' in their news feeds. Arguably, the sender's perspective will not shed light on the way in which photographs are interpreted as the sender's intention may differ to that of the recipient.

\section{Methods}

\subsection{Preliminary studies}

3.1.1 Identifying photographs. A short questionnaire was designed to establish the different content of photographs typically uploaded. Participants formed a convenience sample of Facebook users (25 males, 9 females; $n=34)$, recruited through Facebook and word-of-mouth at a university campus in the UK. Participants had a mean age of 31 years, and were asked to, 'Think back to the last photo(s) you uploaded to Facebook. What and/or whom did it depict?' Participants then described the content of their last uploaded photographs in an open-response text box, and responses were content analysed. That is, researchers identified the different depictions of photograph content by participants, grouped them according to emergent categories, and cross-checked these themes with one another until 100\% agreement was reached. Seven categories of photographic content were identified: self, friend, event, family, scene, objects, and animal. Although these categories could overlap, e.g., a photograph with one's self and friends, the focus of the photographic content as disclosed by participants formed the basis for its classification.

\subsubsection{Users' expectations of photographs in the} news feed. To determine if the seven photograph categories were considered 'expected general day-today sharing', a further survey was conducted, using the same sampling strategy. Participants (8 males, 22 females; $N=30$ ), with a mean age of 32 years, were asked, 'How much do you expect to see the following in your Facebook news feed on a day-to-day basis?' Responses for each category of photograph were given using a 5-point scale anchored at 'completely unexpected' (1) to 'completely expected' (5). Results suggested that participants expected to see all seven photograph types in their Facebook News Feed (all mean scores $>3$; see Table 1 ).

Table 1. User expectations of viewing photographs in the Facebook News Feed

\begin{tabular}{lcc}
\hline $\begin{array}{l}\text { Photograph } \\
\text { Type }\end{array}$ & $\begin{array}{c}\text { Mean } \\
\text { Expectation }\end{array}$ & $\begin{array}{c}\text { Standard } \\
\text { Deviation }\end{array}$ \\
\hline Self & 4.63 & 0.56 \\
Friends & 4.53 & 0.63 \\
Events & 4.27 & 0.64 \\
Family & 4.10 & 1.03 \\
Scenes & 3.60 & 1.00 \\
Objects & 3.23 & 1.10 \\
Animals & 4.03 & 0.96 \\
\hline
\end{tabular}

\subsection{Main study}

A questionnaire was developed with two aims. First, to measure the frequency with which participants perceived their Facebook 'friends' to share the seven types of photograph identified above. Second, to measure relational closeness with participants' Facebook 'friends'. Although Facebook's algorithms change as to how shared content is transmitted to users, it is the recipient's perception of other user's sharing frequency that is investigated herein, as it is the visibility of content that facilitates behavioural and emotional responses. 
3.2.1 Participants. A worldwide but predominantly US sample contained 445 participants (female = 361 ), with a mean age of 25 years (range $=18-62$ years). Of this sample, 62 had achieved a secondary school level education (typical age at completion is 16 years), 18 an A-Level education (typical age at completion is 18 years), 252 participants an undergraduate qualification, 86 a postgraduate education and 27 responded with 'other'. Table 2 shows the nationality of participants. NB: 32 other nationalities were listed but each represented $<1 \%$ of the sample and were combined into a single category.

Table 2. Nationality of participants

\begin{tabular}{lc}
\hline Nationality & No. of Participants \\
\hline USA & 176 \\
UK & 54 \\
New Zealand & 16 \\
Ireland & 12 \\
Canada & 10 \\
Italy & 8 \\
Philippines & 8 \\
Australia & 7 \\
Other & 103 \\
32 Others $<1 \%$ & 51 \\
\hline TOTAL & $\mathbf{4 4 5}$ \\
\hline
\end{tabular}

3.2.2 Design and procedure. A URL was posted to a Facebook research account held by the research group and to John Krantz's psychological studies participation website (http://psych.hanover.edu/research/exponnet.html). The URL randomly allocated participants to one of five survey conditions such that each condition represented one of five relationship types: a relative, partner, close friend, colleague and a general Facebook friend, utilising an independent groups design. These categories were chosen to differentiate between kin (relatives) and non-kin (partners, close friend) relations as there is a difference in the persistence of these relationships [26], and to include work colleagues who may pose a challenge to the management of disclosure privacy in SNS. A general Facebook friend was chosen as they represent a connection with wider acquaintances typically observed in Facebook.

Relatives: Participants in the relative condition were asked to "please choose the relative with whom you are closest who is also on Facebook". Whilst differences in the type of relationships may exist (e.g. sibling, father), it is more poignant that the participant selects their closest relative such that each response is given with a similar degree of closeness. Arguably, selecting a relative such as a mother would restrict responses as not all participants may have their mother on Facebook.

Partners: Those assigned to the partner condition were asked to "choose a boy/girl friend (partner) whom you are dating or have dated. You may choose someone you are seeing now, or someone you went out with previously. If you choose a past boy/girl friend, please answer the questions as you would have when you were in the relationship".

Close Friends: In the close friend condition, participants were asked to "choose the most important friend you have had. You may select someone who is your most important friend now, or who was your most important friend previously. Do not choose a sibling. If you select a person with whom you are no longer friends, please answer the questions as you would have when you were in the relationship".

Colleagues: For colleagues participants were asked to "choose the person who is a colleague of yours but not somebody with whom you would typically socialise".

General Facebook Friends: Last, for general Facebook friends participants were asked to "think of a typical friend with whom you communicate with using Facebook". The wording was adjusted but kept in-line with the original scales in the Network of Relationships Inventory (NRI; instructions were obtained by emailing the authors [35]). The wording within each category was used to reduce the potential for overlap between categories. For example, it is possible to be a close friend with a colleague, however, by asking participants to select a colleague with whom they do not socialise, it was intended that relationships with close friends would not be selected.

Participants completed measures of relational closeness regarding their relationship with the individual in the condition to which they were assigned. Relational closeness was measured using three self-report scales $(1-5 ; 1=$ strongly disagree, 5 = strongly agree) from the NRI, each containing three items. The three scales used were Companionship ( $\alpha$ $=.884$ ), which identifies how much social time participants consider themselves to spend with the other person; Intimacy ( $\alpha=.939)$, to determine how close the participant considers their self and the other person to be; and, Support $(\alpha=.920)$, to determine the degree to which the participant relies on the other person in times of personal need. Participants then completed measures of the perceived frequency at 
which the individual discloses each of the seven photograph types via Facebook (7-point scale: $1=$ least frequent, $7=$ most frequent). Therefore, results are from the recipient's perspective and rely upon self-report measures. Whilst self-report measures depend on the recall and accuracy of the participant, they are typical of the studies within this field $[3,8,23,27]$, and represent an ethical means to investigate a participant's wider network interaction.

\section{Results}

Before commencing the main analysis, the association between perceived frequency of photograph sharing in general and differences in relational closeness were investigated. Thus, a mean was taken across all seven photograph categories and a Photos variable was created, which was subsequently entered as an IV in a MANOVA alongside Relationship Type, Relationship Type*Photos, and Age and Gender to control for their effects. Relational closeness DVs entered were Companionship, Intimacy and Support and multivariate tests were computed (see Table 3).

Photograph sharing in general was not significantly associated with relational closeness. However, a significant multivariate effect was observed between Relationship Type*Photos and the three relational closeness DVs. That photograph sharing varies with relationship type, suggests that the type of relationship held with the discloser is important in this relationship, especially since Photos showed no main effects. As it is known that photographs are formed of distinct depictions, further investigation into the effects of these depictions is warranted.

Table 3. Multivariate results for DVs companionship, intimacy and support

\begin{tabular}{llll} 
IV & Pillai's Trace & F & df \\
\hline Age & $.021^{* *}$ & 4.359 & 3 \\
$\begin{array}{l}\text { Gender } \\
\text { Relationship }\end{array}$ & $.091^{* * *}$ & 19.972 & 3 \\
$\begin{array}{l}\text { Type } \\
\begin{array}{l}\text { Photos } \\
\text { Relationship }\end{array}\end{array}$ & $.081^{* * *}$ & 4.171 & 12 \\
Type*Photos & $.010 \pm$ & 2.073 & 3 \\
\hline
\end{tabular}

$* p<.05 * * p<.01 * * * p<.001 \pm p>.05$

Correlations were calculated for the seven photograph categories (see Table 4). Twenty of the 21 correlations were within acceptable limits ( $\mathrm{r}<$ .700). The correlation of perceived frequency of
Photographs of Friends and Photographs of Events exceeded suggested limits $(r=.743)$. However, a degree of correlation is expected amongst these IVs as differences in the sharing of photograph categories is likely to be small, i.e. different depictions may appear simultaneously in a posted photograph album, and so are likely to be related. Therefore, all seven categories were included in the final analysis for completion.

Table 4. Pearson correlations of the perceived sharing frequency of each photograph category

\begin{tabular}{llllllll}
\hline & a) & b) & c) & d) & e) & f) & g) \\
\hline a) & 1.00 & 0.50 & 0.27 & 0.65 & 0.66 & 0.33 & 0.317 \\
b) & & 1.00 & 0.32 & 0.58 & 0.45 & 0.31 & 0.351 \\
c) & & & 1.00 & 0.37 & 0.43 & 0.49 & 0.515 \\
d) & & & & 1.00 & 0.74 & 0.32 & 0.381 \\
e) & & & & & 1.00 & 0.34 & 0.445 \\
f) & & & & & & 1.00 & 0.486 \\
g) & & & & & & & 1.000 \\
\hline
\end{tabular}

a) Self, b) Family, c) Scenery, d) Friends, e) Events, f) Animals, g) Objects

A MANOVA was conducted with Companionship, Intimacy and Support entered as DVs. Relationship Type and the measures of perceived sharing frequency of the seven photograph categories were entered as IVs. A custom model was created to assess the main effects of each of the seven IVs, and the interaction of Relationship Type*Photo [Category]. Age and gender were entered to control for their effects. Significant results for the multivariate tests and associated univariate tests are shown in Table 5.

Multivariate tests show Relationship Type to be significantly related to relational closeness (the three DVs overall), and univariate tests show this holds for each of Companionship, Intimacy and Support. Photos of Self and Photos of Events are significantly related to relational closeness for each of the three DVs. Multivariate tests are significant for Photos of Family, yet the univariate tests are each nonsignificant, suggesting that photos of family are significant collectively for relational closeness but not against any one DV. The remaining photo types were not significantly related to relational closeness, with non-significant multivariate and univariate tests. Thus, individually the perceived sharing frequency of the seven photograph categories have different relationships with relational closeness, whereby only two are significantly associated.

However, in combination with Relationship Type, four photograph categories were significantly related to relational closeness (Relationship Type*Photos of Self, Relationship Type*Photos of Family, 
Relationship Type*Photos of Friends, and Relationship Type*Photos of Objects). However, on inspection of the univariate results, for Relationship Type*Photos of Family, there is no significant relationship found with Intimacy. For Relationship Type*Photos of Objects, there is no significant association with scores of Companionship or Support. Age and Gender were also significantly associated with relational closeness, but Gender was not related to scores of Companionship and Intimacy.

Table 5. Significant test results for companionship (a), intimacy (b) and support (c)

\begin{tabular}{|c|c|c|c|c|}
\hline \multirow[b]{2}{*}{ IV } & \multicolumn{2}{|c|}{ Multivariate $(\mathbf{a}, \mathbf{b}, \mathbf{c})$} & \multicolumn{2}{|c|}{ Univariate } \\
\hline & $\begin{array}{l}\text { Pillai's } \\
\text { Trace }\end{array}$ & $\mathbf{F}$ & DV & $\mathbf{F}$ \\
\hline Age & .031 & $6.073 * * *$ & $\begin{array}{l}\text { (a) } \\
\text { (b) } \\
\text { (c) }\end{array}$ & $\begin{array}{l}13.752 * * * \\
17.092 * * * \\
14.277 * * *\end{array}$ \\
\hline Gender & .103 & $21.819 * * *$ & $\begin{array}{l}\text { (a) } \\
\text { (b) } \\
\text { (c) }\end{array}$ & $\begin{array}{l}3.515^{ \pm} \\
0.278^{ \pm} \\
13.661 * * * \\
\end{array}$ \\
\hline Rel. Type & .075 & $3.648 * * *$ & $\begin{array}{l}\text { (a) } \\
\text { (b) } \\
\text { (c) }\end{array}$ & $\begin{array}{l}5.720 * * * \\
6.051 * * * \\
7.075 * * * \\
\end{array}$ \\
\hline $\begin{array}{l}\text { Photos of } \\
\text { Self }\end{array}$ & .055 & $11.137 * * *$ & $\begin{array}{l}\text { (a) } \\
\text { (b) } \\
\text { (c) }\end{array}$ & $\begin{array}{l}16.347 * * * \\
29.882 * * * \\
31.655^{* * * *}\end{array}$ \\
\hline $\begin{array}{l}\text { Photos of } \\
\text { Family }\end{array}$ & .025 & $4.893 * *$ & $\begin{array}{l}\text { (a) } \\
\text { (b) } \\
\text { (c) }\end{array}$ & $\begin{array}{l}1.048^{ \pm} \\
0.981^{ \pm} \\
3.402^{ \pm} \\
\end{array}$ \\
\hline $\begin{array}{l}\text { Photos of } \\
\text { Events }\end{array}$ & .015 & $2.932 *$ & $\begin{array}{l}\text { (a) } \\
\text { (b) } \\
\text { (c) }\end{array}$ & $\begin{array}{l}5.893 * \\
8.376 * * \\
7.593 * *\end{array}$ \\
\hline $\begin{array}{l}\text { Rel. Type * } \\
\text { Photos of } \\
\text { Self }\end{array}$ & .049 & $2.388 * *$ & $\begin{array}{l}\text { (a) } \\
\text { (b) } \\
\text { (c) }\end{array}$ & $\begin{array}{l}2.755^{*} \\
4.138 * * \\
2.595 *\end{array}$ \\
\hline $\begin{array}{l}\text { Rel. Type * } \\
\text { Photos of } \\
\text { Family }\end{array}$ & .066 & $3.230 * * *$ & $\begin{array}{l}\text { (a) } \\
\text { (b) } \\
\text { (c) }\end{array}$ & $\begin{array}{l}3.984 * * \\
2.342^{ \pm} \\
5.498^{* * *} \\
\end{array}$ \\
\hline $\begin{array}{l}\text { Rel. Type * } \\
\text { Photos of } \\
\text { Friends }\end{array}$ & .081 & $3.960 * * *$ & $\begin{array}{l}\text { (a) } \\
\text { (b) } \\
\text { (c) }\end{array}$ & $\begin{array}{l}5.036 * * \\
4.580 * * \\
8.210 * * * \\
\end{array}$ \\
\hline $\begin{array}{l}\text { Rel. Type * } \\
\text { Photos of } \\
\text { Objects }\end{array}$ & .046 & $2.202 *$ & $\begin{array}{l}\text { (a) } \\
\text { (b) } \\
\text { (c) }\end{array}$ & $\begin{array}{l}1.997^{ \pm} \\
3.832^{* *} \\
1.497^{ \pm}\end{array}$ \\
\hline
\end{tabular}

$* p<.05 * * p<.01 * * * p<.001 \pm p>.05$
Although the overall test results demonstrate the significance of results, the direction of any associations cannot be determined. Thus, parameter estimates for all three DVs are shown in Table 6, but only IVs that had significant multivariate outcome in Table 5. It should be noted that the MANOVA procedure requires one relationship type to form a dummy function, as such general Facebook friend was entered last for comparison with the other four relationship types.

The perceived frequency at which Photos of Self were shared was significantly negatively related to Companionship, Intimacy and Support, and a negative relationship was also found between Photos of Family and Companionship. However, the perceived sharing frequency of Photos of Family was not significantly related to Intimacy or Support, and for Photos of Events no significant relationships were found with any of the three DVs.

Looking into the association between Relationship Type and Photos of Self, it can be observed that the perception of increased sharing of Photos of Self by Close Friends was positively related to Companionship, Intimacy and Support, but no other associations were significant. For Photos of Family, a significant positive relationship was found for Relatives with Companionship and Support, and for Partners with all of Companionship, Intimacy and Support. No associations between Close Friends and Colleagues with any relational closeness measure were found for Photos of Family. For Partners and Close Friends, a significant negative association was found between perceived frequency of sharing Photos of Friends with Companionship, Intimacy and Support, however no significant effects were found for Relatives or Colleagues. Last, for Photos of Objects, a significant negative association was found only for Partners with Companionship and Intimacy.

Looking into the association between Relationship Type and Photos of Self, it can be observed that the perception of increased sharing of Photos of Self by Close Friends was positively related to Companionship, Intimacy and Support, but no other associations were significant. For Photos of Family, a significant positive relationship was found for Relatives with Companionship and Support, and for Partners with all of Companionship, Intimacy and Support. No associations between Close Friends and Colleagues with any relational closeness measure were found for Photos of Family. For Partners and Close Friends, a significant negative association was found between perceived frequency of sharing Photos of Friends with Companionship, Intimacy and Support, however no significant effects were found for Relatives or Colleagues. Last, for Photos of 
Objects, a significant negative association was found only for Partners with Companionship and Intimacy.

\begin{tabular}{|c|c|c|c|}
\hline IV & Beta (a) & Beta (b) & Beta (c) \\
\hline Age & $-0.02 * * *$ & $-0.03 * * *$ & $-0.02 * * *$ \\
\hline Gender & $-0.17 \pm$ & $0.06 \pm$ & $0.37 * * *$ \\
\hline Relative & $-0.34 \pm$ & $-1.42 *$ & $-1.62 *$ \\
\hline Partner & $0.69 \pm$ & $-0.02 \pm$ & $-0.04 \pm$ \\
\hline Close Friend & $0.61 \pm$ & $-0.00 \pm$ & $-0.65 \pm$ \\
\hline Colleague & $-0.83 \pm$ & $-1.59 *$ & $-1.82 * *$ \\
\hline Photos of Self & $-0.20^{*}$ & $-0.30 * *$ & $-0.39 * * *$ \\
\hline Photos of Family & $-0.22 * *$ & $-0.04 \pm$ & $-0.11 \pm$ \\
\hline Photos of Events & $0.11 \pm$ & $0.05 \pm$ & $0.03 \pm$ \\
\hline $\begin{array}{l}\text { Relative * Photos } \\
\text { of Self } \\
\text { Partner * Photos }\end{array}$ & $0.01 \pm$ & $-0.06 \pm$ & $0.15 \pm$ \\
\hline $\begin{array}{l}\text { of Self } \\
\text { Close Friend * }\end{array}$ & $0.02 \pm$ & $-0.00 \pm$ & $0.12 \pm$ \\
\hline $\begin{array}{l}\text { Photos of Self } \\
\text { Colleague * }\end{array}$ & $0.25^{*}$ & $0.36^{* *}$ & $0.36^{* *}$ \\
\hline Photos of Self & $-0.04 \pm$ & $0.02 \pm$ & $0.17 \pm$ \\
\hline $\begin{array}{l}\text { Relative * Photos } \\
\text { of Family }\end{array}$ & $0.32 * *$ & $0.15 \pm$ & $0.24 *$ \\
\hline $\begin{array}{l}\text { Partner * Photos } \\
\text { of Family } \\
\text { Close Friend } *\end{array}$ & $0.35 * *$ & $0.28 *$ & $0.50 * * *$ \\
\hline $\begin{array}{l}\text { Photos of Family } \\
\text { Colleague * }\end{array}$ & $0.11 \pm$ & $-0.05 \pm$ & $0.10 \pm$ \\
\hline Photos of Family & $0.15 \pm$ & $-0.00 \pm$ & $0.05 \pm$ \\
\hline $\begin{array}{l}\text { Relative } * \text { Photos } \\
\text { of Friends }\end{array}$ & $-0.16 \pm$ & $0.05 \pm$ & $-0.16 \pm$ \\
\hline $\begin{array}{l}\text { Partner * Photos } \\
\text { of Friends } \\
\text { Close Friend } *\end{array}$ & $-0.51 * * *$ & $-0.54 * *$ & $-0.75 * * *$ \\
\hline $\begin{array}{l}\text { Photos of Friends } \\
\text { Colleague * }\end{array}$ & $-0.40 * *$ & $-0.33^{*}$ & $-0.32 *$ \\
\hline Photos of Friends & $-0.11 \pm$ & $-0.08 \pm$ & $-0.07 \pm$ \\
\hline $\begin{array}{l}\text { Relative * Photos } \\
\text { of Objects } \\
\text { Partner * Photos }\end{array}$ & $0.02 \pm$ & $0.14 \pm$ & $0.04 \pm$ \\
\hline $\begin{array}{l}\text { of Objects } \\
\text { Close Friend * }\end{array}$ & $-0.24^{*}$ & $-0.33 *$ & $-0.22 \pm$ \\
\hline $\begin{array}{l}\text { Photos of Objects } \\
\text { Colleague * }\end{array}$ & $-0.01 \pm$ & $0.01 \pm$ & $-0.03 \pm$ \\
\hline Photos of Objects & $-0.14 \pm$ & $0.07 \pm$ & $0.03 \pm$ \\
\hline
\end{tabular}

These results suggest that for some photograph types, a direct relationship is found between perceived sharing frequency by the recipient and their reports of relational closeness overall.

However, when taking into account the type of relationship held with the discloser, different associations are found with relational closeness, and in some cases the association is in the opposite direction. For example, Photos of Self are negatively related with Companionship, Intimacy and Support, yet when broken down into relationship types, it is evident that this association becomes positive when the discloser of such photographs is a Close Friend.

These results suggest that for some photograph types, a direct relationship is found between perceived sharing frequency by the recipient and their reports of relational closeness overall. However, when taking into account the type of relationship held with the discloser, different associations are found with relational closeness, and in some cases the association is in the opposite direction. For example, Photos of Self are negatively related with Companionship, Intimacy and Support, yet when broken down into relationship types, it is evident that this association becomes positive when the discloser of such photographs is a Close Friend.

Thus, overall it can be seen that photograph disclosure is associated with differences in relational closeness, and this association may differ when taking into account the relationship held with the sender of posts. However, it cannot be ascertained from the survey data why these relationships might exist, and future research is necessary.

\section{Discussion}

The results showed that the perceived frequency at which certain photographs were shared on Facebook was significantly associated with differences in three components of relational closeness, and were often dependent on relationship type. Thus, RQ1a, RQ1b and RQ2 are addressed, and the following key contribution is provided: the perceived frequency of the disclosure of different non-text based content is significantly related to differences in companionship, intimacy and support. Moreover, this relationship type can alter this association. Whilst only addressing this through the lens of photographic content and from the recipient's perspective, this research provides the necessary first steps into understanding disclosure other than text the CMC equivalent of verbal disclosure. However, future research is necessary to investigate the full extent of this relationship. 


\subsection{Photograph content and perceived frequency}

The perceived frequency at which photographs were shared was significantly associated with companionship, intimacy and support, depending on the photographic depiction (content). Receiving photographs of self and family at different perceived frequencies was associated with different levels of companionship (photos of self, photos of family), intimacy (photos of self) and support (photos of self). For these two categories of photograph, this association was found to be negative overall, and represents the only significant finding for the links between photograph disclosure and relational closeness as a main effect. This suggests that photographs in general are benign. That is, there are few differences in relational closeness based purely on the photographic content and the perceived frequency of its reception, but relationship type is important in the interpretation of photographs (discussed later). This provides insight to understanding that increased sharing does not always mean increased intimacy or relational closeness.

\subsection{Relationship type, photograph content and perceived frequency}

An important finding of the present study is that the posting of photographs is received by users more or less favourably based upon the type of relationship they hold with the sender. In the quantitative data, it can be seen that the negative associations between sharing photographs of self and family, can become positive when particular others are perceived to post them increasingly. For photos of self, a positive relationship is found when the disclosure occurs by close friends, and for family photographs, the association becomes positive when shared by relatives and partners (in the latter case adding significant associations with intimacy and support that are not found when photographs of family are examined without relationship type). Thus, the ability to communicate support with others through Facebook [29] is evident in the disclosure of photographs, with increases in support found for photographs of family (when shared by relatives and partners) and photographs of self (when shared by close friends). Moreover, the importance of the interpretation by the recipient of photographic disclosures is identified, noting that differences in the content within a feature can have different outcomes, striking harmony with the effects found by channel affordances and recipient interpretation [9].
However, perceived frequency at which partners with whom participants are close - share photographs of objects is negatively associated with companionship and intimacy. Thus, this tolerance and favour for those close to us may have its own threshold of acceptance (although arguably photographs of objects are not likely to fulfil a companionship or intimacy need). Consequently, future research is needed to begin to unpick the causation within these mechanisms and investigate potential moderators, such as frustration, social judgement and acceptance. Last, the frequency at which photographs of friends was perceived to be shared by partners and close friends, was negatively associated with scores of companionship, intimacy and support. At first this finding seems strange. However, when taking into consideration the measures of relational closeness, it is possible that this type of sharing, depicting relationships with others and friend groups more widely, does not serve the individual interpersonal needs of companionship, intimacy and support. Thus, the use of photographs to signal the importance of relationships with others may be beneficial when that signalling is on a one-toone basis. Conversely, when signalling affection toward a wider group, this may not benefit the oneto-one relationships also present in the same virtual space. Such differences in interpersonal goals may impact on the way in which individuals choose to use photograph sharing, similarly to the way they can choose features for different purposes [22].

More broadly, this study supports work from $\mathrm{CMC}$ and pre-CMC eras, identifying the importance of relationship type for the disclosure and reception of information [3,4,13,14]. Furthermore, it contributes to the knowledge on relational maintenance through SNS. In line with prior work investigating CMC and affordances of SNS $[4,8,12]$, it is evident that the frequency and content of disclosure through photographs can serve a relationship escalation, maintenance or de-escalation function. Associations with companionship, intimacy and support were found to be negative, positive, or have no significance. That is, depending on the photographs, relationships are either improved, are not effected or are diminished, and therefore it is important for users and site designers to understand how each of these outcomes may be achieved, intentionally or unintentionally. Similarly, to linguistic differences whereby users post more positive emotion words in public, non-directed channels [7], when posting public, non-directed photographs senders should aim for the content to be positive, i.e. that a recipient is favourable to such content, and these should not be shared to excess 
frequency, violating the normative rules of Facebook [27]. Thus, the present research provides some initial insight into the relationships between photographic disclosure and relational closeness, demonstrating some general patterns, but has begun to uncover a more complex set of associations, which require future enquiry to investigate their precise nature.

\section{Limitations}

Despite the strength of this paper, future research is required to uncover the causal mechanisms by which such outcomes occur. In addition, there are several noteworthy limitations. 1) Self-report data leave a margin of error in the responses given by participants. 2) By measuring frequency using Likerttype scales it cannot be ascertained precisely as to what is considered "too frequent". 3) Typical Facebook engagement metrics ('likes', sharing and comments) and simultaneous offline interaction were not considered herein and could impact the relationship between photograph disclosure and relational closeness. 4) The sample consists of predominantly younger female participants with US nationality, and the multiple nationalities herein are under-represented. However, the sample obtained is argued to be more representative than that formed from a single nationality or global region.

\section{Conclusion}

With the prevalent use of social media such as Facebook and the active encouragement such sites give users to post content (e.g. Facebook's status update text-box asks "what's on your mind?"), understanding the effects of the interaction between frequency and content in online communication is essential. Furthermore, the scarcity of research into non-text based disclosure highlights a more general gap in knowledge. Thus, the present findings provide a significant contribution to the field. Perceived sharing frequency is related both positively and negatively to relational closeness dependent on the photographic content and relationship type, and thus serving different relational maintenance goals. Therefore, sharing more frequently can be both beneficial and costly to relational closeness, and even for typically appropriate and expected information in Facebook (i.e. "mundane", [4]), users should consider the consequences of sharing to excess, and crowding their Facebook network. For site operators, encouragement of users to share information is not always positive. Disclosure may be detrimental to the users' relationships with their audiences, and negative consequences of using a social platform could lead to a general decrease in its use.

\section{References}

[1] Facebook. (2016). Company Info, accessed http://newsroom.fb.com/company-info/ $30^{\text {th }}$ September 2016.

[2] Guardian. (2014a). Facebook: 10 Years of Social Networking, in Numbers, accessed http://www.theguardian.com/news/datablog/2014/feb/04/fac ebook-in-numbers-statistics $6^{\text {th }}$ September 2015.

[3] Ledbetter, A. M., Mazer, J. P., DeGroot, J. M., Meyer, K. R., Mao, Y., \& Swafford, B. (2011). Attitudes Toward Online Social Connection and Self-Disclosure as Predictors of Facebook Communication and Relational Closeness. Communication Research, 38(1), 27-53.

[4] Tong, S. T., \& Walther, J. B. (2011). Relational Maintenance and CMC. In K. B. Wright \& L. M. Webb (Eds.), Computer-mediated communication in personal relationships (pp. 98-118). New York: Peter Lang Publishing.

[5] Ellison, N., Steinfield, C., \& Lampe, C. (2007). The benefits of Facebook" Friends:" Social Capital and College Students' Use of Online Social Network Sites. Journal of Computer-Mediated Communication, 12(3), 1143-1168.

[6] Joinson, A. N. (2008). 'Looking at', 'looking up' or 'keeping up with' people? Motives and uses of Facebook. Paper presented at the CHI 2008 - Online Social Networks, Florence, Italy.

[7] Bazarova, N. N., Taft, J. G., Choi, Y. H., \& Cosley, D. (2012). Managing Impressions and Relationships on Facebook: Self-Presentational and Relational Concerns Revealed Through the Analysis of Language Style. Journal of Language and Social Psychology, 32, 121-141.

[8] Sosik, V. S., \& Bazarova, N. N. (2014). Relational Maintenance on Social Network Sites: How Facebook Communication Predicts Relational Escalation. Computers in Human Behavior, 35, 124-131.

[9] Bazarova, N. N. (2012). Public Intimacy: Disclosure Interpretation and Social Judgments on Facebook. Journal of Communication, 1-18. doi: 10.1111/j.14602466.2012.01664.x

[10] Park, N., Jin, B., \& Jin, S. A. (2011). Effects of SelfDisclosure on Relational Intimacy in Facebook. Computers in Human Behavior, 27, 1974-1983.

[11] Guardian. (2014b). The Rise and Rise of Instagram, accessed http://www.theguardian.com/travel/2014/oct/17/rise-ofinstagram-london-instameet $6^{\text {th }}$ September 2015. 
[12] Jiang, L. C., Bazarova, N. N., \& Hancock, J. T. (2011). The Disclosure-Intimacy Link in Computer-Mediated Communication: An Attributional Extension of the Hyperpersonal Model. Human Communication Research, $37,58-77$.

[13] Jourard, S. M. (1959). Self-Disclosure and OtherCathexis. The Journal of Abnormal and Social Psychology, 59(3), 428-431.

[14] Altman, I., \& Taylor, D. A. (1973). Social penetration: The development of interpersonal relationships. USA: Holt, Rinehart and Winston, Inc.

[15] Chelune, G. J. (1979). Self-disclosure: Origins, patterns, and implications of openness in interpersonal relationships. San Francisco, Washington, \& London: Jossey-Bass.

[16] Jourard, S. M., \& Lasakow, P. (1958). Some factors in self-disclosure. Journal of Abnormal Psychology, 56(1), 9198 .

[17] Collins, N. L., \& Miller, L. C. (1994). Self-Disclosure and Liking: A Meta-Analytic Review. Psychological Bulletin, 116(3), 457-475.

[18] Tidwell, L. C., \& Walther, J. B. (2002). Computermediated communication effects on disclosure, impressions, and interpersonal evaluations: Getting to know one another a bit at a time. Human Communication Research, 28(3), 317348 .

[19] Walther, J. B. (1996). Computer-Mediated Communication: Impersonal, Interpersonal, and Hyperpersonal Interaction. Communication Research, 23(1), $3-43$.

[20] Joinson, A. N. (2003). Understanding the Psychology of Internet Behaviour: Virtual Worlds, Real Lives. London: Palgrave MacMillan.

[21] Donath, J. (2008). Signals in Social Supernets. Journal of Computer-Mediated Communication, 13(1), 231-251.

[22] Bazarova, N. N., \& Choi, Y. H. (2014). Self-Disclosure in Social Media: Extending the Functional Approach to Disclosure Motivations and Characteristics on Social Network Sites. Journal of Communication. doi: 10.1111/jcom.12106

[23] McEwan, B. (2013). Sharing, Caring, and Surveilling: An Actor-Partner Interdependence Model Examination of Facebook Relational Maintenance Strategies. Cyberpsychology, Behavior, and Social Networking, 16(12), 863-869.

[24] Lampe, C., Gray, R., Fiore, A. T., \& Ellison, N. B. (2014). Help is on the way: Patterns of Responses to Resource Requests on Facebook. Paper presented at the
Computer-Support Cooperative Work, Baltimore, MD, USA.

[25] Gilbert, E., \& Karahalios, K. (2009). Predicting Tie Strength With Social Media. Paper presented at the CHI 2009, Boston, MA, USA.

[26] Roberts, S. G. B., \& Dunbar, R. I. M. (2010). The costs of family and friends: an 18-month longitudinal study of relationship maintenance and decay. Evolution and Human Behavior.

[27] Bryant, E. M., \& Marmo, J. (2012). The Rules of Facebook Friendship: A Two-Stage Examination of Interaction Rules in Close, Casual, and Acquaintance Friendships. Journal of Social and Personal Relationships, 29, 1013-1035.

[28] Joinson, A. N., Houghton, D. J., Vasalou, A., \& Marder, B. L. (2011). Digital Crowding: Privacy, SelfDisclosure and Technology. In S. Trepte \& L. Reinecke (Eds.), Privacy Online: Perspectives on Privacy and SelfDisclosure in the Social Web (pp. 31-44). Heidelberg and New York: Springer.

[29] Mansson, D. H., \& Myers, S. A. (2011). An Initial Examination of College Students' Expressions of Affection Through Facebook. Southern Communication Journal, 76(2), 155-168.

[30] Stefanone, M. A., \& Lackaff, D. (2009). Reality Television as a Model for Online Behavior: Blogging, Photo, and Video Sharing. Journal of Computer-Mediated Communication, 14, 964-987.

[31] Marder, B. L., Shankar, A., Houghton, D. J., \& Joinson, A. (In Press). 'What if my mum sees it?': Examination of visible brand interaction in the presence of a wider network. Information Technology and People.

[32] Jones, S., \& O'Neill, E. (2011). Contextual Dynamics of Group-Based Sharing Decisions. Paper presented at the Proceedings of the SIGCHI conference on Human factors in computing systems, Vancouver, BC, Canada.

[33] Binder, J., Howes, A., \& Sutcliffe, A. (2009). The Problem of Conflicting Social Spheres: Effects of Network Structure on Experienced Tension in Social Network Sites. Paper presented at the CHI 2009, Boston, MA, USA.

[34] Marder, B. L., Joinson, A., Shankar, A., \& Houghton, D. J. (2016). The extended 'chilling' effect of Facebook: The cold reality of ubiquitous social networking. Computers in Human Behavior, 60, 582-592. doi: http://dx.doi.org/10.1016/j.chb.2016.02.097

[35] Furman, W., \& Buhrmester, D. (1985). Children's perceptions of the personal relationships in their social networks. Developmental Psychology, 21(6), 1016-1024. 